\section{(IN)JUSTICIA TERRITORIAL EN EL PROCESO DE URBANIZACIÓN. EL CASO DE MANIZALES ${ }^{1}$}

\author{
Lina María Zuluaga Giraldo² y Adolfo León \\ Grisales Vargas ${ }^{3}$
}

\section{Resumen}

Teniendo en cuenta el caso específico de la ciudad de Manizales (Colombia), este artículo presenta la forma cómo la planificación apropiada en el proceso de urbanización de la ciudad, desde la década del treinta del siglo XX hasta la actualidad, ha generado desigualdades y polarizaciones, y con ello, injusticias sociales hacia grupos carentes de capital económico y poder político como los ubicados en los barrios populares autoconstruidos en las ladera del sur de Manizales, injusticias que se ven reflejadas en el espacio. Se explican las desigualdades urbanas surgidas a partir de un estudio histórico y se realiza una reflexión crítica frente a los

\section{TERRITORIAL (IN)JUSTICE IN THE PROCESS OF URBANIZATION: THE CASE OF MANIZALES ${ }^{1}$}

\author{
Lina María Zuluaga Giraldo² and Adolfo León \\ Grisales Vargas ${ }^{3}$
}

\section{Abstract}

Taking the specific case of Manizales (Colombia) as an example this paper shows how planning within the urbanization process has generated inequality and polarization since the 1930s and in doing so has brought about social injustice for groups lacking economic and political power. An example of this are the self-help neighborhoods located in the southern slopes of Manizales where injustices are clearly reflected in the local space. Based on a historical study, this paper explains the emergence of urban inequalities and reflects critically on planning processes by establishing how urban space is produced in terms of social, economic 
procesos de planificación, estableciendo la manera cómo se da la producción del espacio urbano, desde las relaciones sociales, económicas y políticas, las cuales indefectiblemente se reflejan en las formas espaciales que asume la ciudad. Finalmente, se plantea la búsqueda por una justicia territorial, en el marco del ensamblaje espacial, histórico y social, que genere formas más efectivas para cambiar las desigualdades y polarizaciones mediante prácticas y políticas espacialmente conscientes, pasando de un enfoque basado en modelos distributivos a cuestiones procedimentales de participación y toma de decisiones, a través de la acción social y política concertada.

\section{PALABRAS CLAVE: SEGREGACIÓN ESPACIAL; DESIGUALDAD SOCIAL; JUSTICIA TERRITORIAL; DERECHO A LA CIUDAD.}

Recibido: 23-11-2017

Aceptado: 27-08-2018

1 Este artículo surge como resultado parcial de la investigación doctoral en Estudios Territoriales de la Universidad de Caldas titulada “Los barrios populares autoconstruidos en las laderas del sur de Manizales a partir de la década de los 70, como espacialidad de la resistencia; y como una reflexión teórica para fundamentación del fenómeno estudiado".

2 Colombia. Profesora Escuela de Arquitectura y Urbanismo Universidad Nacional de Colombia, sede Manizales. ORCID: http://orcid. org/0000-0001-8060-4346. Correo electrónico: Imzuluagag@unal. edu.co.

3 Colombia. Profesor Departamento de Filosofía Universidad de Caldas. ORCID: https://orcid.org/0000-0002-4385-858X. Correo electrónico: adolfo.grisales@ucaldas.edu.co. and politically-based relations, which are inevitably expressed in the spatial forms taken by the city. Finally, we stress the need to search for territorial justice within the contexts of spatial, historical and social assembly to generate more effective tools aimed at changing inequalities and polarization. This could be pursued by implementing spatiallysensitive policies and practices, thus shifting from a distributive model approach to procedural-based participatory and decision-making approaches through social action and concerted policies.

KEY WORDS: SPATIAL SEGREGATION; SOCIAL INEQUALITY; TERRITORIAL JUSTICE; RIGHT TO THE CITY.

Received: 23-11-2017

Accepted: 27-08-2018

1 This paper presents partial findings of a doctoral research in Territorial Studies at the University of Caldas entitled "Self-help popular neighborhoods in the southern slopes of Manizales since the 1970s, the emergence of a spatiality for resistance and a theoretical reflection to support the phenomenon under review".

2 Colombia. Professor, School of Architecture and Urban Planning, National University of Colombia. ORCID: http://orcid.org/0000-00018060-4346. Email: Imzuluagag@unal.edu.co.

3 Colombia. Professor, Department of Philosophy, Caldas University. ORCID: https://orcid.org/0000-0002-4385-858X. Email: adolfo.grisales@ucaldas.edu.co. 


\section{Introducción}

En el proceso de urbanización ocurrido a partir del modo de producción industrial se gestan injusticias que afectan significativamente una población pobre residente en la ciudad. Para efectos de abordar dicho fenómeno, este artículo se desarrolla en tres apartados. El primero de ellos está fundamentado especialmente en los postulados de Soja (2010, 2008), Bauman (2001), Zambrano y Bernard (1993), Aprile-Gniset (1992), Giraut (2008) y Rafesttin (s.f.), quienes establecen el modo en que las formas de organización espacial expresan los intereses de aquellos con poder económico y político de acuerdo con un modo de producción dado, pero además, cómo dichos intereses, casi siempre, son apoyados por el Estado a través del "control del espacio", el que a su vez, empieza a ser partícipe en la generación de injusticias. A partir del trabajo realizado por Aprile-Gniset sobre la ciudad colombiana, se presenta el caso de Manizales estableciendo desde sus orígenes las formas de dominación del espacio mediante un proceso de mercantilización del suelo urbano, así como la manera en que una población excluida de dicho mercado, en su afán de resolver el problema de tierra y techo a través de la invasión de predios y mediante la autoconstrucción de sus casas, genera el fenómeno que denominamos "barrio popular autoconstruido".
La denominación de "barrio" - para efectos de este artículo y de la investigación en general- se asume no desde la condición político administrativa como unidad básica territorial en la ciudad, de acuerdo con la normatividad colombiana; sino como aquel espacio donde se desarrolla la vida urbana cotidiana de sus pobladores, por tanto, les permite un dominio social sobre él, en donde la proximidad entre vecinos permite el reconocimiento mutuo. Así, y tal como lo proponen Certeau, Giard y Mayol (1999, p. 9), el barrio es ese trozo de ciudad que atraviesa un límite que distingue el espacio privado del espacio público. Un espacio que efectivamente está marcado por límites físicos, pero también simbólicos, con fragmentaciones interiores que contempla diferentes actores con jerarquías variables y produce formas cotidianas de experiencias que construyen el lazo social entre vecinos, aunque no elimina el surgimiento de contradicciones y conflictos.

Ahora bien, la denominación "barrio popular autoconstruido" se establece para el barrio que surge a partir del saber y las prácticas tradicionales, que es construido por sus propios pobladores para satisfacer las necesidades del habitar cotidiano, pero además, donde se da la participación de estos en la construcción y toma de decisiones sobre el espacio físico. De esta manera, la morfología urbana se va dando espontáneamente como una adaptación a sus necesidades, sin corresponderse con la 
racionalidad de los diseños urbanos proyectados técnicamente. Incluso aquellas viviendas que fueron construidas por el Estado, son transformadas desde ese saber popular.

En el segundo apartado, y de acuerdo con lo propuesto por Mattos (2010, 1999), Soja (2010, 2008), Carlos (2003, 2001) y Santos (1990), se muestra cómo las injusticias en los procesos de urbanización, se han venido intensificando en las últimas décadas debido a las políticas neoliberales instauradas en países como Colombia, las cuales se ven materializadas en la ciudad de Manizales, llevando a una privatización de lo público, una disminución considerable del Estado de bienestar y unas formas de planificación con enfoque empresarial que favorecen los intereses de privados y las clases mejor acomodadas.

Finalmente, en el tercer apartado se plantea una reflexión en torno a la justicia territorial, estableciendo las condiciones que producen injusticias sociales en la ciudad de Manizales, así: la mala distribución de los recursos, la opresión y la dominación. Por lo anterior, se plantea la búsqueda por una buena distribución, pero además, por una acción social y política concertada de todos los habitantes de la ciudad en la toma de decisiones respeto a su espacio urbano, a través de presiones y luchas que permitan lograr el derecho a la ciudad.

\section{Metodología}

El "barrio popular autoconstruido", de acuerdo a la denominación dada con antelación, se aborda como ensamblaje histórico, social y espacial, por tanto, se entiende en tanto producción social del espacio a través de una construcción en el tiempo y como resultado de múltiples relaciones, entre ellas las relaciones de poder, que van configurando la ciudad, convirtiéndose así en espacio material y simbólico que presenta tanto aspectos formales como procesuales o dinámicos; de esta manera y en síntesis, cuando hablamos de este barrio, hablamos de un territorio.

Por consiguiente, para realizar la lectura de este territorio se tiene en cuenta su condición espacial, buscando su articulación con la sociedad que le dio lugar y con su modo de inserción a ella, razón por la cual, no se indaga el barrio popular autoconstruido exclusivamente a partir del espacio perceptible o material, como configuración y práctica de la vida urbana de quienes lo habitan -enfoque principal de los estudios urbanos y arquitectónicos- sino que se aborda como una producción social que se va dando en el proceso de urbanización de la ciudad de Manizales. Así, teniendo en cuenta lo dicho por Zambrano y Bernard (1993) 
de que cada sociedad, en cada época determinada y en el marco de un sistema económico específico produce una cierta formación y ordenación del espacio, se tuvo en cuenta: la sociedad que da lugar a la producción del espacio, las formas de producción de dicha sociedad, el momento histórico, las normas que se adoptan en la organización del espacio y las relaciones de poder que surgen en este proceso.

De acuerdo con lo anterior, se realiza un análisis histórico-espacial, estableciendo a través del tiempo y dentro de un devenir histórico, las acciones que de manera escalar han influido en la organización espacial de Manizales y han afectado los barrios populares autoconstruidos en las laderas del sur (Figura 1). De esta manera, se interpretan momentos de hibridación y conflicto para revelar las relaciones de poder-saber dentro de las cuales se dan las formaciones de estos barrios.

El territorio es entendido como una complejidad de redes, vínculos, prácticas, intercambios, en el espacio, por esta razón, es interpretado como el resultado de la mezcla distinta de todas las prácticas e intercambios que se entrelazan dentro de él, pero además, lo vuelven producto de lo que se desarrolle como resultado del entrelazamiento.

Adicionalmente, fundamentados en la teoría críti$c a$, se realiza un análisis de las polarizaciones y contradicciones que durante las últimas décadas se han presentado en la ciudad de Manizales.
Polarizaciones y contradicciones surgidas por la planificación llevada a cabo, proporcionándose como un servicio casi siempre para favorecer a los habitantes mejor acomodados, de acuerdo con Soja, incluso en nombre de la lucha contra la pobreza, ya que las necesidades de servicios urbanos no han sido ignorados por completo para las población más pobre, pero están sistemáticamente subordinadas a las necesidades y expectativas de los que viven por encima de la línea de pobreza (Soja, 2010, p. 20). Esta particular manera de pensar la ciudad ha planteado que por prestar el servicio a la mayoría de la población, una estrategia aparentemente admirable, no es discriminatoria; y entonces, ¿qué ha pasado con la población que habita los barrios populares autoconstruidos en las laderas del sur de Manizales?

Metodológicamente, desde una perspectiva crítica espacial se debe preguntar sobre que ocurre en el espacio y por qué, quién se beneficia y a quién se perjudica, metodología que debe ser histórica y socialmente contextualizada, con el fin de producir la irrupción de algo más significativo: el surgimiento de una práctica activa que está dirigida conscientemente por nociones cada vez más espacializadas de justicia social, democracia participativa, y derechos y responsabilidades de los habitantes (Soja, 2010). De acuerdo con lo anterior, la justicia en este caso, no legitima el sacrificio de una persona o un sector de la sociedad en beneficio de la mayoría. 
FIGURA 1. LÍNEA DEL TIEMPO. ANÁLISIS HISTÓRICO-ESPACIAL.

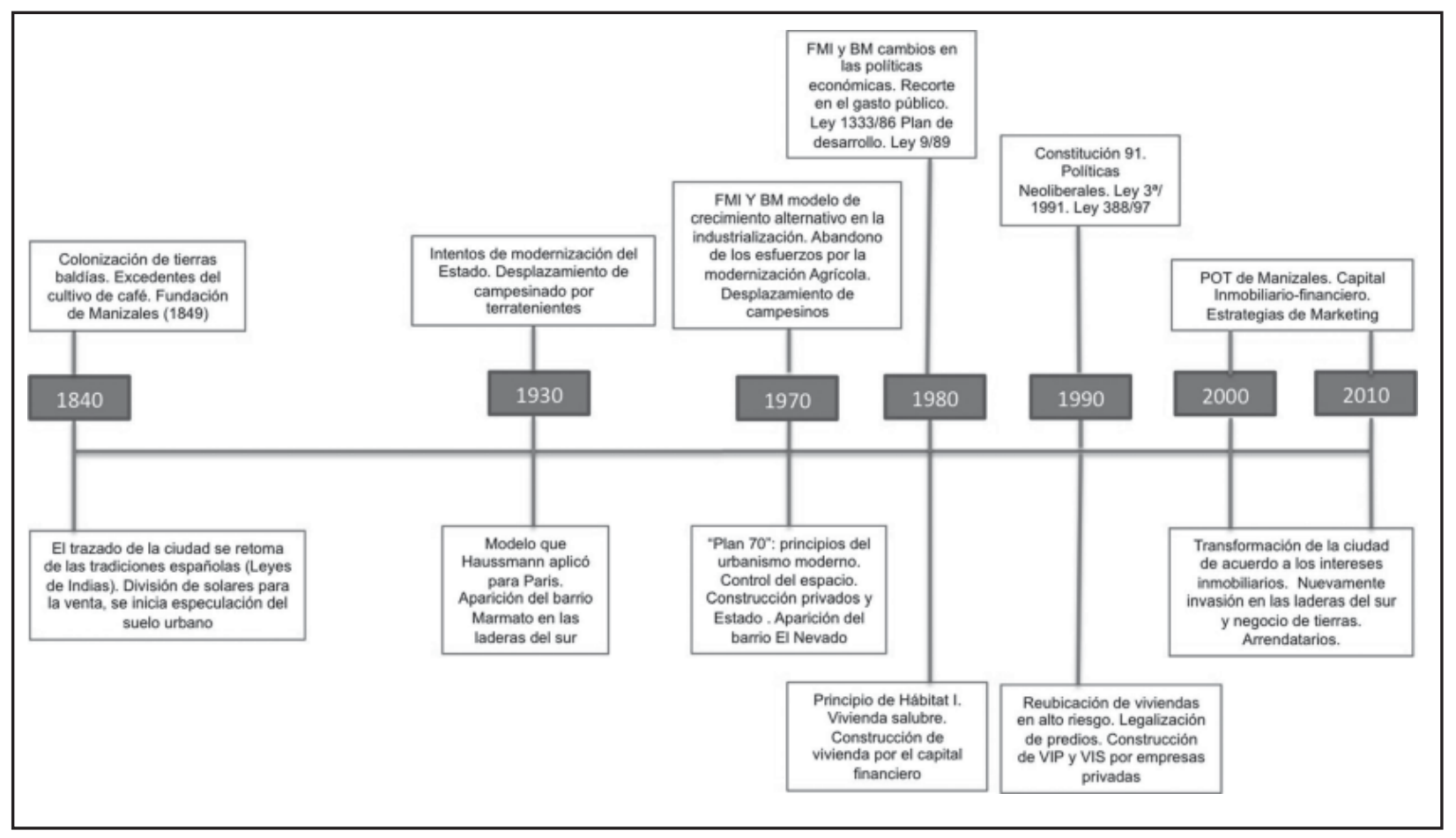

Fuente: elaboración propia. 


\section{Resultados}

\section{LA PRODUCCIÓN SOCIAL DEL ESPACIO URBANO Y EL BARRIO POPULAR AUTOCONSTRUIDO. EL CASO DE MANIZALES}

Cuando hablamos de espacio urbano nos referimos a la relación entre el proceso social que se da a partir del modo de producción industrial y la forma espacial que genera en la ciudad, expresando las normas "según las cuales son estructurados, regulados y construidos los fenómenos urbanos" (Harvey, 1973, p. 319).

Según Soja (2008), las formas espaciales expresan los intereses de grupos dominantes de acuerdo con un modo de producción dado. Fundamentados en lo anterior, desde la modernidad se ha dado esta dominación a partir de un cambio en la producción predominantemente agraria a industrial, lo cual llevó al fortalecimiento de la organización espacial urbana, en donde el "Estado crea la ciudad y sobre la ciudad el Estado toma lugar" (Zambrano y Bernard, 1993, p. 13), convirtiéndose a su vez en residencia de poder. Dice Aprile-Gniset:

"[c]oincide históricamente el nacimiento de la ciudad con la especialización técnica de la producción, la división social del trabajo, la consecución de un excedente, su apropiación por un segmento social (...) la aparición de una clase dominante y el Estado: siendo la primera un instrumento indispensable del último. Así la ciudad se puede definir como la expresión espacial y el reflejo de un hecho histórico y social: el nacimiento del Estado." (Aprile-Gniset, 1992, p. 770).

Esta manera de producción del espacio urbano se puede encontrar en Colombia a partir de la creación de la república, cuando se da inicio a un proceso de colonización de tierras baldías, que acuerdo con Aprile-Gniset, se da de diferentes maneras: colonización popular de campesinos sin tierras, colonización mercantil y empresarial con fines económicos, colonización estatal con motivaciones esencialmente políticas (Aprile-Gniset, 1992, p. 782-783); y a la emergencia de una red de ciudades producto de la acumulación agraria, como indicativo del poder del Estado mediante la instalación de sus instituciones. Se funda así la ciudad de Manizales a mediados del siglo XIX a partir del excedente del cultivo de café. En este proceso de fundación se presentan conflictos entre colonos campesinos, los cuales fundan el derecho a la propiedad a través del trabajo, y las empresas mercantiles que reclaman propiedad mediante títulos que son concedidos por capitulaciones reales (Aprile-Gniset, 1992, p. 115-167). Finalmente, con el fin de dirimir el conflicto y desarrollar aún más la ciudad, el Estado entra a comprar parte de las tierras a la empresa González-Salazar; sin embargo, sobre los demás predios de su propiedad esta compañía continúa vendiendo solares a los 
colonos campesinos que siguen llegando, creándose de esta manera un ambiente mercantilista y generando un proceso de especulación del suelo urbano. Con lo anterior, se evidencia un conflicto social en el origen mismo de la ciudad de Manizales convirtiéndose en el centro de dominio económico y político de estas empresas, quienes empiezan a configurar y organizar el espacio de acuerdo con sus intereses.

La ciudad, gracias a los excedentes del café y al impulso que el cabildo empieza a dar a la industria mediante la promoción y establecimiento de una fábrica de hilados y tejidos de cabuya ("Archivo Historial de Manizales", 1920), se configura como el eje de representación de la clase dominante, la cual se apropia de la zona céntrica a través del proceso de reconstrucción desarrollado durante la década del treinta del siglo XX después de los incendios ocurridos entre 1924 y 1926, en palabras de Robledo, "con un modelo propio de rentas del suelo altísimas" (Robledo, 1992, p. 227). Esta reconstrucción se basa en una arquitectura ajustada a la estética francesa -neoclasicismo-, que en Colombia tomará el nombre de "Estilo Republicano" en el que la presencia de aspectos neoclásicos se carga de elementos de orden criollo, dejando como resultado una arquitectura ecléctica (Giraldo, 1985, p. 92), donde se aplica un saber técnico con el aporte por primera vez de profesionales de la arquitectura y se utiliza una nueva tecnología: el concreto armado; urbanísticamente, aunque se conserva la cuadrícula española (Figura 2) se lleva a cabo el ensanche de las vías, en busca de la movilidad vehicular. Lo anterior muestra una ideología adoptada como forma de representación del poder político y económico. Adicionalmente, se institucionalizan normas que permiten una sectorización de la ciudad en un intento de haussmannización de esta, pero además, que determinan las formas y tecnologías constructivas (Giraldo, 1985), expulsando así a una población que no puede cumplir las normas impuestas, debido a su poca capacidad económica; un informe del presidente del concejo de Manizales en 1925, lo demuestra: "Afortunadamente con el incendio de estas piezas, tuvieron los obreros que retirarse a sitos apartados del centro de la ciudad" (Arango, 1925, p. 38).

Es para este período del treinta cuando el Estado colombiano asume su deber de productor de vivienda, dice Jiménez: el Estado asumió su función pública, de esta manera, crea el Banco Central Hipotecario - $\mathrm{BCH}-$, para apoyar la construcción de vivienda para clases obreras y se ordena a los municipios asignar presupuesto para esta (Jiménez, 2009). Ya en Manizales, entre 1922 y 1927, se había iniciado la construcción de este tipo de vivienda en el Barrio Vélez (Figura 2), como un negocio del constructor Roberto Vélez; sin embargo, y como lo describe Giraldo (2001), el municipio también impulsa la construcción de habitaciones 
para obreros a través de la "Junta del proletariado". Todo este tipo de vivienda se desarrolla en la periferia del centro de la ciudad, especialmente hacia el oriente, manteniendo la tendencia a colocarse en la parte más alta de la montaña, en donde las casas son construidas mediante una mixtura de técnicas tradicionales (bahareque) y materiales modernos (cemento y vidrio), adaptándose a la topografía pendiente de manera escalonada.

De igual manera, una parte de la nueva clase exportadora e industrial apropiada de la zona céntrica, busca salir y alejarse de esta, haciéndose esto posible por la llegada del automóvil. Se construyen entonces quintas en el Barrio Versalles (Figura 2) sobre terrenos con poca pendiente. El barrio se trabaja bajo el concepto de ciudad jardín, con un patrón de rentas diferente al del centro de la ciudad pues por estar en la periferia el costo del suelo es menor, pero además, con una morfología urbana que dista del trazado en damero y que permite adaptarse a la topografía.

En todo este proceso, una población carente de poder económico y político no puede acceder a la tierra ni construir con las normas establecidas o acceder a un crédito hipotecario. Por tanto, esta población empieza a ubicarse en la periferia sobre las laderas norte y sur, resolviendo por ellos mismos su problema de vivienda, invadiendo en el caso de las laderas del sur terrenos pertenecientes al ferrocarril de Caldas, apareciendo así el barrio Marmato (Figura 2). Adicionalmente, aquellos que podían, compraban a buenos precios las peores tierras de la periferia incentivando la urbanización pirata. Según Robledo (1992), para los propietarios de estas tierras ahora sí era rentable promover la urbanización de estas laderas.

Se inicia entonces en Manizales una fragmentación y segregación social y espacial, en donde en las tierras con mejores condiciones topográficas y con mejores servicios e infraestructura se localiza la nueva clase comercial e industrial dueña del excedente económico, pero además que logra un poder político. En las tierras de regular condición se ubica la clase obrera; y las peores tierras, en donde la pendiente de la ladera es demasiado pronunciada con riesgos por remoción de masas, se ubica una población carente de capital económico y poder político. La desigualdad económica y política genera una desigualdad social que se espacializa en la ciudad desde el origen mismo de esta, lo cual produce injusticias hacia una población pobre. 


\section{FIGURA 2. MANIZALES, DÉCADA DEL TREINTA.}

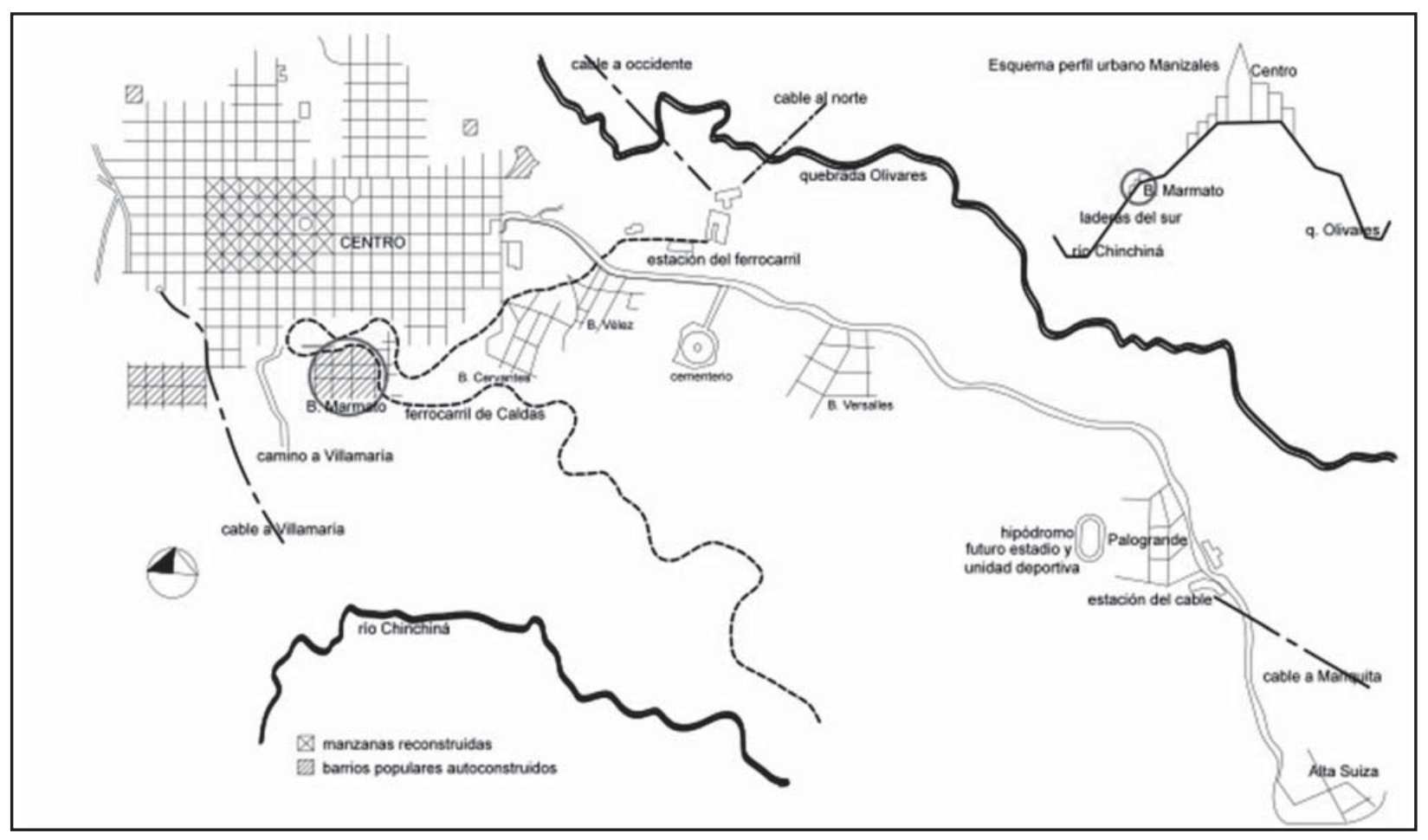

Fuente: elaboración propia, basado en Robledo (1992). 
Es a partir de los años treinta y hasta los setenta que se da una explosión demográfica en la ciudad por un aumento poblacional debido, de un lado, al incremento de natalidad, y de otro, a la llegada de un gran número de campesinos a la ciudad, esto último, como consecuencia del impulso que el Estado colombiano le da a la industrialización por sustitución de importaciones, iniciándose un proceso de descomposición del campesinado debido a la penetración capitalista en la estructura agraria, lo cual genera una migración de la mano de obra campesina a la ciudad en busca de trabajo dentro de la nueva industria. En Manizales para esta época se fomentó dicha actividad por parte de la Cámara de Comercio; así, entre 1945 y 1970 los cuatro subsectores principales en que se agrupa la industria manizaleña son: trilla de café $61 \%$, alimentos 25\%, bienes de consumo tradicional 10\% y el resto de actividades 4\% (Giraldo, 2001, p. 173). Sin embargo, esta actividad es bastante incipiente y no tiene el auge esperado, por tanto, no logra acoger toda la mano de obra que llega del campo.

La llegada del campesinado a la ciudad no solo se da por la penetración capitalista, sino también, y según Aprile-Gniset (1992), debido al desplazamiento de colonos campesinos por parte de terratenientes que reclaman propiedad sobre las tierras lo que genera intensas luchas rurales. Esta explosión demográfica se da también por el desplazamiento de los campos y no solo por la atracción de la ciudad como fuente de empleo. Así, una población campesina empobrecida llega a la ciudad, no encuentra empleo ya que la incipiente industria no logra acogerlos, ni pueden desarrollar otras formas de actividad productiva que les permita adquirir algún capital, por tanto, dicha población no tiene los medios para acceder al mercado inmobiliario, quedando excluidos del suelo y la vivienda dentro de la ciudad, pero también, de servicios básicos e infraestructura.

Por lo anterior, se empieza a producir un mayor poblamiento de las laderas del sur de Manizales mediante la autoconstrucción, con empleo parcial o exclusivo de la mano de obra familiar, forma productiva y laboral dominante en la producción de vivienda, consolidándose así el "barrio popular autoconstruido", lo que Aprile-Gniset explica de la siguiente manera: "una colonización urbana y solidaria, concertada y organizada, con el desmonte de un pastizal para transformarlo en barrio. Una colonización colectiva con los convites dominicales para realizar unos indispensables banqueos en laderas muy inclinadas" (Aprile-Gniset, 1992, p. 622).

En palabras de Aprile-Gniset, con la guerra rural y la crisis que afecta la empresa popular de la colonización agraria, se inicia la colonización urbana; forma de poblamiento que se convierte en una expresión distintiva de la fase moderna de la urbanización no solo de Manizales, sino de Colombia en general. Así, los barrios populares autoconstruidos se convierten en un rasgo característico de la 
ciudad moderna colombiana. En Manizales las tierras con mayor pendiente que circundaban el centro, consideradas como inconstruibles, como las laderas del sur, se integran a la ciudad por medio de un verdadero proceso de colonización popular, pudiéndose afirmar que el espacio urbano nuevo, en gran parte, es producto del trabajo de colonos sin techo que no encuentran trabajo en la ciudad, y en cierto modo, este fenómeno es el traslado de la violencia que migró del campo a la ciudad.

En la ciudad, a estos colonos se les niega la tierra, el techo, pero además el trabajo, lo que genera una injusticia social, por lo que esta población tendrá que inventar sus fuentes de empleo, de recursos y de protección en el medio urbano a través de una creatividad popular espontánea, surgida de las mismas penurias. De esta manera, las acciones de estos colonos se van territorializando en lo que Safa y Aceves (2006) llaman una "ciudad de la invención", en la cual surgen relatos de vida que oscilan entre las oportunidades limitadas y las opciones casi inexistentes; así, sus pobladores van hilvanando identidades, inventando espacios y ciudades desde su condición de pobreza y vulnerabilidad.

De esta manera se va configurando la espacialidad urbana de Manizales generando una verdadera fragmentación y segregación a través de una localización en el suelo urbano, las cuales se agudizan con el tiempo debido a la aplicación de los postulados del movimiento moderno en arquitectura para la ciudad, donde se pretenden una zonificación marcada que clasifica la construcción de grandes vías que permitan conectar las diferentes zonas y la delimitación de las futuras áreas de expansión como principios ordenadores y armónicos de la ciudad. De esta manera, el espacio es concebido por expertos, codificado en representaciones como el plano, de ahí que sea dominado por la técnica y el poder político para su control.

Es así como para la década del cuarenta se propone un plan ordenador para la ciudad. Debido a la presencia del urbanista Karl Brunner en 1940 y con la llegada de una nueva generación de arquitectos a la ciudad se quiere implementar los principios del movimiento moderno con una base racional, según lo demuestra el discurso de Brunner en el paraninfo del palacio municipal el 3 de mayo de 1940:

"El planeamiento urbano de la ciudad futura no es solamente un paso imprescindible para los proyectos del acueducto y alcantarillado, sino también una base para iniciar una acción a favor de la urbanización racional de los nuevos sectores de ensanche" (Giraldo, 1985, p. 230).

Pero además dicho plan responde a la ola que hay en Colombia tendiente a realizar los planos reguladores de las principales ciudades en concordancia con la ley del congreso nacional de 1947, que ordena para los municipios con presupuesto mayor a \$200.000 la obligación de elaborar un plan 
regulador. Surge desde esta época la inquietud por realizar una planeación de la ciudad desde las oficinas municipales y por estimular una reglamentación urbana que permita un aprovechamiento del suelo.

Para las décadas del cincuenta y el sesenta, se comienzan a aplicar en la ciudad los consejos y enseñanzas de Brunner en cuanto a la zonificación de áreas, aprovechamiento de algunos sectores para vivienda y cesiones para áreas de recreación. Asimismo, y como respuesta a las políticas de las entidades oficiales, como el Banco Central Hipotecario $(\mathrm{BCH})$, el Instituto de Crédito Territorial (ICT) y la Caja de la Vivienda Popular (CVP) y ante el preocupante déficit habitacional se construyen barrios para albergar la población campesina que sigue llegando, pero, según Giraldo (1985), ante la necesidad de encontrar terrenos a bajo costo y fácilmente edificables, esto debido a la topografía abrupta de la ciudad, se comienza una progresiva retirada del casco urbano haciendo centros satelitales, en los cuales se albergará una población obrera, generando una expansión de la ciudad.

En los años setenta y continuando con esta política estatal, en 1971 el ICT emprende el barrio El Nevado en las laderas del sur, en límites con la antigua carrilera del ferrocarril sobre terrenos que ya habían empezado a ser invadidos, construyendo 400 casas prefabricadas para solucionar el problema de los damnificados de barrios deprimidos de la ciudad a causa de un fuerte invierno. Posteriormente, se construye una segunda etapa por la CVP, y para finales de esta década se inicia la toma de tierras en las laderas inferiores al barrio, las cuales presentan una marcada pendiente.

Es para esta década del setenta, y debido a la creciente necesidad que manifestaban las autoridades municipales de establecer un ordenamiento planificado de la ciudad, que se formula el "plan 70", consistente en el primer plan de desarrollo de Manizales, en el cual se mantienen las fórmulas urbanas regidas por las ideas del movimiento moderno. Se establece así una zonificación clara para la ciudad, nuevas vías para la articulación del suelo urbano y las áreas de futuro crecimiento. Con ello, se legaliza el reparto social del suelo a través de la regulación y control de su uso, naturaleza e intensidad. Engendrado en el derecho, se estructura el espacio físico urbano, con una búsqueda de racionalidad, de la ciudad progreso, que se difunde y se convierte en la visión hegemónica. Sin embargo, esta planificación va de la mano con la dilatación del espacio vital.

Así las cosas, el espacio urbano moderno empieza a ser sometido al poder del Estado para su control, pero también para el control del dinero, del trabajo y de la organización industrial en los términos de Raffestin (1989), ya que se instaura un orden a través de una división territorial que asigna funciones. El Estado entonces practica una 
geometrización del espacio como función de poder para generar una estructura legible y transparente, convirtiéndose así la arquitectura y el urbanismo en instrumentos para el control, el sometimiento y la vigilancia, puesto que "la disciplina realiza primero la distribución en el espacio" (Foucault, 1979). Se aplican entonces los principios de la Carta de Atenas como una estrategia de dominación que fragmenta el espacio y lo hace equivalente de cara al mercado, reuniendo de esta manera en piezas homogéneas y funcionales, la vida del espacio y el espacio mismo. Así, bajo la apariencia de racionalidad, la dominación se expresa en una cotidianidad programada donde se manipulan las necesidades y los deseos.

El plan se convierte en la "condición única [...] de la felicidad humana, que no puede basarse sino en la perfecta articulación de necesidades [...] definidas científicamente y la disposición unívoca, transparente y legible del espacio vital" (Bauman, 2001, p. 59). Así, el plan conduce al "espacio concebido", vinculado a las relaciones de producción, al "orden" que imponen y, de ese modo, a los conocimientos, signos, códigos y relaciones frontales. Es decir, aquel espacio producido a partir de un saber técnico, en donde los usuarios experimentan pasivamente lo que les ha sido impuesto (Lefebvre, 2013, p. 92-100), un "espacio mental" (Soja, 2008) conceptualizado en representaciones como el mapa. En este caso, la producción del espacio genera nuevas formas locales, urbanas y regionales de organización social, estableciendo una función y forma fija para las prácticas sobre él.

\section{LAS POLÍTICAS NEOLIBERALES EN LA PRODUCCIÓN DEL ESPACIO URBANO}

En la década de los ochenta entran en escena las políticas neoliberales a Colombia, las que de acuerdo con Soja, forjan una nueva síntesis que racionaliza, celebra y promueve con eficacia el proceso de globalización, el intercambio comercial, la integración financiera y el flujo de la información (Soja, 2008). Lo anterior ha hecho que una nueva clase de empresarios económicos, financieros y políticos operen no solo a nivel transnacional, sino también nacional, regional y local.

Para el caso de Manizales estas políticas han permitido que el capital privado tenga libertades y ventajas en sus inversiones dentro del suelo urbano, con un retorno maximizado de dicho capital. Como se enunció anteriormente, desde la década del setenta la ciudad empieza a expandirse fuertemente con la construcción de barrios obreros en la periferia del casco urbano, y es para la década del ochenta y noventa cuando se urbanizan los intersticios que quedaban entre el consolidado suelo urbano y los nuevos centros satélites, aprovechando la infraestructura vial y de servicios que la municipalidad había extendido hasta los nuevos barrios 
obreros; por tanto, aquellos predios a urbanizar adquirieron un buen precio dentro del mercado inmobiliario, lo que fomento la construcción por parte del capital privado de vivienda para estratos medios, mucha de la cual fue financiada a través de hipotecas permitiendo la participación, cada vez mayor, de dicha clase en este mercado. Es así como la construcción de vivienda por parte del Estado para los estratos más bajos, sale beneficiando el mercado inmobiliario, en donde la expansión de la ciudad no solo se da geográfica o geométricamente, sino también como una expansión en la mercantilización del suelo y la vivienda, convirtiéndose estos en bienes de consumo.

Entonces, si el suelo y la vivienda se vuelven bienes de consumo, se vuelven a la vez en objetos de especulación, por ser una mercancía muy particular debido a los costos y beneficios que los diferentes servicios urbanos les generan en cuanto a accesibilidad y proximidad a ellos. Se aprecia en el caso de Manizales cómo se controlan estos mecanismos ocultos a través del poder político y administrativo en el manejo de la ciudad; ya se hacían críticas al respecto, precisamente por las injusticias que generaba esta forma de producción de la ciudad. Giraldo expone un documento que para la época circulaba por la ciudad:

"los asentamientos institucionales que surgen de la política del Estado (ICT, CVP), para dar vivienda a los estratos de bajos ingresos, apareciendo un nuevo "orden formal" de unidades habitacionales en la periferia urbana, tales como Malabar, La Sultana, Minitas, Aranjuez, etc., donde el valor de los terrenos es en algunos casos igual o un poco mayor al del suelo agrícola. Sin embargo, con esta acción lo que hacen las políticas de vivienda es presionar la dispersión urbana, agravar la situación de los consumidores al alejarlos de las fuentes de trabajo y de consumo, incrementar los gastos de transporte y; privilegiar los propietarios de terrenos entre los conjuntos habitacionales construidos y el perímetro urbano". (Giraldo, 1985, p. 454).

Igualmente, en estas décadas del ochenta y el noventa, y en concordancia con las conferencias de Hábitat I y Hábitat II, pero además, con las políticas estatales, se llevan a cabo procesos de reubicación de vivienda con problemas de riesgo, se conceden títulos de propiedad y se realizan obras para el mejoramiento barrial. Las entrevistas realizadas a antiguos funcionarios del ICT, que para la época ocupaban cargos administrativos y directivos, dan cuenta de ello: se emprenden programas y proyectos para los habitantes de las laderas del sur que habían poblado estas zonas a través de la toma de tierras; una parte de esta población fue reubicada en barrios como Villahermosa y la urbanización El Paraíso financiados por el ICT y la CVP en áreas periféricas donde el costo del suelo era bajo, las áreas despejadas fueron declaradas como suelo de protección. A otra parte de la población le fue dado el título de propiedad de los predios ocupados y se emprendieron trabajos de mejoramiento de viviendas, así como mejoramiento de taludes, 
tratamiento de laderas y construcción de vías de comunicación peatonal (escaleras). Igualmente, de acuerdo con las entrevistas realizadas, se encontró que durante la administración de los alcaldes Kevin Ángel en el período 1988-1990 y Vitoria Eugenia Osorio en el período 1990-1992, una de las políticas impulsadas para la ciudad era "Manizales sin tugurios"4.

De esta manera, la política para la época era erradicar y arrasar a los ocupantes de estos asentamientos y llevarlos a nuevos barrios, continuando con la política estatal de los años setenta, basada en una condición derecho-ocupante. Así, el Estado interviene a fin de atenuar el problema de la vivienda para aquella población sin recursos, permitiendo que estos accedan al mercado a través de la vivienda de interés social, pero además, crea situaciones jurídicas como la legalización de predios, resolviendo de manera precaria y provisional la falta de propiedad.

En las décadas siguientes el papel del Estado frente a aquellos que no poseían vivienda se limitó a suprimir cualquier tipo de obstáculo que afectara el accionar del mercado. Así, para los años noventa y la primera década de 2000, una estrategia fue desarrollar el "derecho de propiedad" continuando con políticas de regularización a través de los mejoramientos barriales, ello además, en consonancia con uno de los postulados del Consenso de Washington: "redefinir y hacer accesible al conjunto de la sociedad de los derechos de propiedad". Sin embargo, estas políticas de regularización, sin negar lo altamente valoradas que fueron y siguen siendo para los habitantes de los llamados barrios informales, no se plantean como el derecho universal de un lugar para habitar, ya que en la mayoría de los casos no se da como un mejoramiento integral.

Para la misma época en la ciudad de Manizales, se intensifica la inversión privada en la construcción de vivienda para estratos medios y altos, apoyada por el capital financiero, vivienda ubicada en suelos con buena localización y con valor agregado debido a las actividades sociales urbanas que los servicios a su alrededor generan.

De acuerdo con todo lo anterior, se aprecia la persistencia de polarizaciones y desigualdades, las cuales imponen según Mattos (1999), la percepción social de un incremento de la delincuencia y la conflictividad, la que comienza a tener influencia en la formación de espacialidades urbanas y, en consecuencia, en la estructura y la apariencia de la ciudad. Soja y Mattos plantean cómo se intensifica el control social y espacial debido a la privatización, al control policial, a la vigilancia y al gobierno. Así, el diseño del espacio urbano produce unas islas de confinamiento y control como una

4 Tugurios: asentamientos surgidos a través de la toma de tierras. 
colección de ciudades carcelarias en archipiélago, de recintos normalizados y espacios fortificados para los mejor acomodados, lo que impide la integración social. Este fenómeno que se refuerza en la ciudad de Manizales a partir de los años noventa, se ha venido intensificando en los últimos años hacia las áreas de expansión de la ciudad (Figura 3). En los términos de Soja (2008), se observa una inédita tendencia a mezclar el diseño urbano, la arquitectura y la maquinaria policial en una sola estrategia de seguridad, que prohíben el paso al "otro", al de la clase inferior.

En esta nueva forma de organización espacial participa activamente el capital inmobiliario-financiero. Así, el Plan de Ordenamiento Territorial (POT) de Manizales se corresponde con esta nueva forma, facilitando la mercantilización de la ciudad, pero además, la gestión con un "enfoque empresarial” (Mattos, 2010). La planificación propuesta a partir de la ley 388 de 1997 -Ley de Desarrollo Territorial-, establece un escenario apropiado para que los actores privados gocen de plenas libertades con el fin de dirigir sus inversiones dentro de la ciudad entre los puntos que representen una mayor rentabilidad. De esta manera, la libertad de los productores inmobiliarios para guiar sus inversiones dentro de la ciudad permiten, por un lado, que la ciudad se desborde y, por otro, que las desigualdades socio-espaciales produzcan una mayor fragmentación; así, la ciudad es expandida y fragmentada en partes desarticuladas, social, espacial, económica y culturalmente.

La nueva forma de planificación considera los intereses de los pobres urbanos como un juego de suma cero. Tal como establece Smolka (2002), la sobrerregulación del uso del suelo hace que las condiciones de ocupación definidas por la legislación vigente sean inalcanzables para los sectores de bajos ingresos, lo cual los conduce a que deban satisfacer sus necesidades de techo y de la vida urbana en general, reproduciendo las formas de los primeros colonos campesinos, es decir, produciendo sus propios barrios, los que no se corresponden con las nuevas formas de diseño del espacio urbano, sino que son construidos por sus pobladores desde sus necesidades y deseos, en muchas ocasiones mediante la autoorganización que resulta de decisiones y acciones adoptadas cotidianamente por los actores que habitan en ellos. En el mismo sentido, se inicia un negocio de tierra en estos lugares, en términos de Abramo, el ciclo de las grandes ocupaciones de tierras urbanas está ya inflexionando y las tomas de esta adquieren en la actualidad una dinámica de monetización; de la misma manera ocurre con el techo, ya que los grupos que no tienen un salario mínimo y están excluidos de los programas públicos de vivienda, entran en la ciudad por la vía del mercado a través del alquiler, pero no del mercado formal, sino del mercado popular informal (Abramo en Escallón, 
FIGURA 3. DESARROLLO URBANO DE MANIZALES EN LOS ÚLTIMOS AÑOS. TIPOLOGÍA EN ARCHIPIÉLAGO.

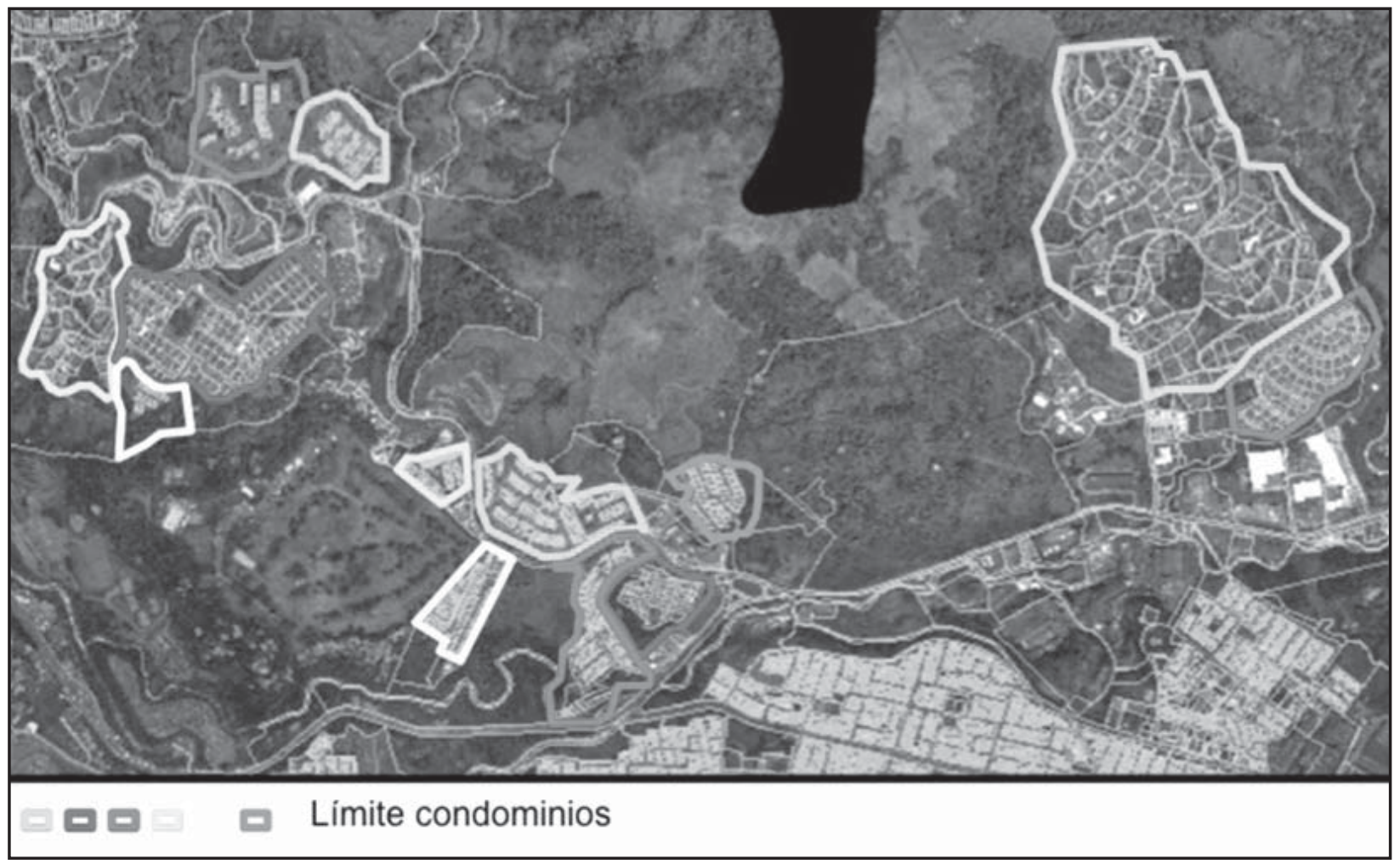

Fuente: Elaboración propia, mapa base Sistema de Información Geográfica (SIG) municipio de Manizales.

2010). Un ejemplo de lo anterior, lo constituye el crecimiento acelerado que han sufrido los barrios populares autoconstruidos en las laderas del sur de Manizales a partir de la década de 2000.
Las apreciaciones sobre estos barrios han tenido prevalencia en los aspectos que podrían señalarse como patológicos, al asumirlos como lo anormal, de ahí las diferentes denominaciones: informales, 
marginales, asentamientos precarios, divisiones irregulares y barrios subnormales. Igualmente, las denominaciones de algunas instituciones estatales como barrios clandestinos o ilegales, tienen un claro enfoque jurídico, haciendo alusión al cumplimiento de requerimiento de propiedad, normas urbanísticas y de construcción. Adicionalmente, son considerados lugares de miedo, porque como lo establecen Pradilla, Galván y Márquez (2012), estos barrios se "guetifican", se ven sometidos al control de bandas armadas, muchas veces ligadas al narcotráfico y a otras formas de delincuencia organizada.

Con la reproducción de estos barrios, las nuevas formas de control del espacio que generan estructuras perfectamente legibles con el fin de ser inmunes a toda manipulación, a cualquier iniciativa desde abajo, empiezan a ser condicionadas por la resistencia de los sujetos marginados, porque ante el Estado la sociedad civil en general se manifiesta por flujos de muchos tipos, lo que Raffestin (1989) llama el "dominio de la micropolítica". En este caso, porque no todos los barrios en la ciudad moderna de Manizales surgen desde una concepción técnica o científica, sino que, además, surgen desde sus habitantes, de los usuarios, es decir, emergen del habitar cotidiano.

Todo lo anterior demuestra una persistencia histórica de injusticias y desigualdades urbanas, convirtiéndose en una de las leyes principales de la estructuración de la ciudad. Desde la formación misma de Manizales hasta el día de hoy opera una separación social y económica del ámbito residencial que se refleja en el espacio. Las formas de organización y planificación se han convertido en una máquina de generación de desigualdades que actúa libremente, manipulada por grupos que buscan la maximización de sus beneficios de acuerdo con una forma de producción y apoyada, en muchos casos, por la legislación del Estado, cuyo objetivo explícito es la mercantilización de la ciudad, lo que lleva a una exclusión y marginación de las poblaciones menos favorecidas.

\section{JUSTICIA TERRITORIAL PARA EL ESPACIO URBANO}

Las desigualdades y polarizaciones, y con ello, las injusticias que producen las formas de planificación que han prevalecido durante las últimas décadas en ciudades como Manizales, si bien generan reflexiones críticas en torno a dichas formas, lo que Soja (Albino y Barsky, 1997) ha denominado "una conciencia espacial crítica", también generan reflexiones por la búsqueda de una justicia territorial, que entre otras, permita una mejor distribución de los recursos dentro de la ciudad, teniendo en cuenta que la desigualdad distributiva es la expresión más básica y obvia de la injusticia en el espacio urbano, como se observa históricamente en la ciudad de Manizales, debido a los efectos 
diferenciales en la localización de un grupo de la población respecto de: los servicios que generan actividades sociales (educación, salud, comercio, entre otros); la infraestructura que permite, por ejemplo, buena conectividad con el resto de la ciudad y servicios básicos para la vida humana (agua, recolección de aguas residuales, energía); y los ingresos, que por su ubicación, puede recibir la población. Por lo anterior, el no contar con una buena localización y con los efectos agregados que esta produce, genera territorios segregados y marginados dentro de la ciudad.

Pero si bien, y tal como lo proponen Fraser (2008) y Rawls (2012) la mala distribución genera injusticias sociales, es necesario entender también que en la ciudad las especificidades espaciales que producen desigualdades y polarizaciones trabajan para fundar y mantener injusticias, alimentadas por la dominación y la opresión hacia grupos desfavorecidos que son marginados. Unas especificidades espaciales donde aquellos grupos con poder económico y político acceden al suelo urbano mejor localizado, ya que pueden pagar por este, pero también influir en las decisiones sobre la ciudad, a través de la forma de planificación que ha imperado durante las últimas décadas permitiendo cada vez más una mercantilización y especulación del suelo urbano, de esta manera, se da un dominio por parte de dichos grupos sobre la organización de la ciudad, pero a la vez, este tipo de organización se vuelve la forma dominante de planificación.
Otros grupos pueden acceder al suelo de medianas condiciones, gracias a su incorporación al sistema financiero, mediante la vivienda de interés social. Y los grupos que quedan excluidos del mercado inmobiliario por falta de capital económico y poder político, deben resolver su problema de vivienda construyendo por ellos mismos sus casas y sus barrios, como los barrios populares autoconstruidos en las laderas del sur de Manizales.

Esta dominación, que surge desde el modo de planificación que ha asumido los postulados de racionalidad y orden del movimiento moderno en arquitectura y que han sido utilizados para favorecer la mercantilización y especulación del suelo urbano, genera visiones duales de la ciudad: formal-informal, legal-ilegal y centro-periferia. Dominación originada principalmente en nombre de la razón, que según Soja (2008) ha llevado a ver la primera parte de esta visión como lo sagrado, lo divino, el bien común, la ciudad de la razón, la democracia; y la segunda, como lo profano, lo irracional, el pecado. Un dualismo que refleja un pensamiento moderno que ha dominado los últimos tiempos y que constituye un modo de disciplinar el mundo en opuestos rígidamente limitados.

Este pensamiento genera unos imaginarios urbanos de orden político, social y cultural, que en palabras de Lindón (2007) dan cierto sentido a un lugar atribuyéndole características a través de calificativos particulares. Así, los barrios populares autoconstruidos, como los de las laderas del sur 
de Manizales, son calificados como irregulares o subnormales, generando una "mala valoración" (Fraser, 2008), y con ello, una opresión hacia los grupos que allí habitan, teniendo en cuenta que Young (2000) propone cinco aspectos en la opresión: explotación, marginación, carencia de poder, imperialismo cultural y violencia. Ya que al designarle significados simbólicos que la gente asocia con menosprecio, a menudo afectan de modo significativo la situación social de sus habitantes y sus oportunidades, etiquetándolos y silenciando su autoexpresión, lo que indefectiblemente impide que éstos ejerzan de manera plena sus derechos políticos, porque tal como lo plante Davis (2007) el proceso de toma de decisiones sobre la ciudad se produce al margen del voto popular, entonces aunque los habitantes del barrio popular autoconstruido en las laderas del sur de Manizales tienen derecho al voto, no tienen pleno derecho de decidir conjuntamente el destino de la ciudad.

Más que reforzar una división bipartita entre incluidos y excluidos, se debe optar por una visión que tenga en cuenta las complejas dinámicas sociales generadas por las desigualdades que emergen a partir del modo de planificación dominante de la ciudad de Manizales en las últimas ocho décadas. Así, y aunque los llamamientos por una buena distribución en el espacio urbano en busca de justicia son sin duda importantes, la dominación y la opresión también son términos centrales para conceptualizar injusticias (Young, 2000), entonces el propósito por la búsqueda de justicia debe tender a soluciones que pongan fin a las fuentes de opresión y dominación, de esta manera, la idea de justicia pasa de un enfoque basado en modelos distributivos a cuestiones procedimentales de participación y toma de decisiones, es decir, a tener en cuenta que si se reconocen las injusticias en el espacio urbano y estas han sido construidas socialmente, están abiertas, asimismo, a modificarse a través de la acción social y política concertada.

Una acción social y política que permita a todos los habitantes de Manizales, y no solo a los grupos dominantes, tomar decisiones con respecto a su espacio urbano, a la forma como la ciudad debe organizarse. De ahí que consideremos a Ricoeur (2006) cuando propone que la justicia es la regla práctica más elevada por constituir el punto donde culmina el deseo del vivir bien, ligado al cuidado de sí mismo, al cuidado del otro y al cuidado de las instituciones; un buen vivir que contiene, en palabras de Young, dos valores: "participar en la determinación de nuestra acción y de las condiciones de nuestra acción; y, desarrollar y ejercer nuestras capacidades y expresar nuestra experiencia" (Young, 2000, p. 67). En suma, tanto Ricoeur como Young entienden por justicia la toma de decisiones en las circunstancias singulares de un proceso, que para el caso específico sería el proceso de planificación de Manizales, dentro de sus correspondientes instituciones; pero además, remiten a la idea de capacidad, lo cual permite asegurar que toda vida 
humana cuenta por igual y que nadie es más importante que otro, es decir, al reconocimiento de unos y otros.

Adicionalmente, al involucrar un pensamiento crítico espacial (Soja, 2010), en donde se reflexione sobre la forma como las desigualdades se van espacializando en la ciudad, se plantea la búsqueda por una "justicia espacial" (Soja, 2010), la cual no sustituye la noción de justicia social, sino que, más bien privilegia el espacio como categoría de análisis válida para interpretar las condiciones que producen injusticias, además de abrir en el marco del ensamblaje espacial, histórico y social, formas más efectivas para cambiar las desigualdades y polarizaciones a través de prácticas y políticas espacialmente conscientes.

Así, la participación en la producción del espacio urbano de todos como socios en pleno derecho a la interacción social, permitirá presionar y ganar luchas no solo en busca del reconocimiento de todos, sino también, luchas sobre lo que se conoce como el "derecho a la ciudad". Este útimo, tal como lo formuló en principio Lefebvre (1978), restablece los fundamentos urbanos de la búsqueda por la justicia, la democracia y los derechos de los ciudadanos, ya que de no ser así, el funcionamiento normal de la vida urbana diaria, sería generador de relaciones de poder desiguales, que se manifiestan sucesivamente en distribuciones injustas de los recursos sociales a todo lo largo y ancho del espacio urbano, pero además, en fuente de opresión y dominación. Por tanto, la exigencia de mayor y mejor acceso al poder social y a los recursos para los más desfavorecidos, define la lucha por las reclamaciones de los diversos derechos, en un esfuerzo continuo por la reapropiación espacial, que reivindicará una presencia activa en todo lo que concierne a la vida urbana.

\section{Conclusiones}

Es necesario considerar las relaciones sociales, económicas, culturales y políticas con la manera en que la ciudad asume ciertas formas espaciales. Es así como en Manizales una sociedad industrial incipiente encuentra su realización en la urbanización, asumiendo los principios del movimiento moderno en arquitectura para la organización de la ciudad, siendo aprovechados para el dominio espacial, y con ello, para la mercantilización y especulación del suelo urbano. Todo esto genera desigualdades en el espacio, llevando a la marginación y segregación de grupos carentes de capital económico y poder político como los ubicados en los barrios de las laderas del sur.

En la actualidad el dominio espacial se da mediante una planificación con enfoque empresarial, buscando la reproducción acelerada del capital, pero además, generando una fragmentación y difusión 
de la ciudad. Así, las relaciones mencionadas forman parte activa en la creación y mantenimiento de dominaciones, desigualdades y opresiones que conllevan a una serie de injusticias. Por tanto, la generación de una política espacial explícita, proporcionará una fuerza vinculante para combinar aquellas formas de resistencia y lucha en busca de una justicia territorial.

La desigualdad ha prevalecido como práctica en la planificación urbana, favoreciendo grupos dominantes y conduciendo a la opresión de grupos, como aquellos que habitan los barrios populares autoconstruidos en las laderas del sur de Manizales. De acuerdo con lo anterior, las injusticias están vinculadas directamente con la mala distribución de los recursos en la ciudad, pero además, con la dominación y la opresión. Sin embargo, la búsqueda por una mejor distribución, así como la acción social y política concertada, permitirán búsquedas por una justicia territorial, a través de presiones y luchas para lograr lo que se ha denominado el "derecho a la ciudad".

\section{Referencias bibliográficas}

Albino, S. y Barsky, A. (1997). El tercer espacio. Ampliando el horizonte de la imaginación geográfica (Edward Soja). Geographikós, (8), 71-76.

Aprile-Gniset, J. (1992). La ciudad colombiana. Siglo XIX y siglo XX. Santafé de Bogotá: Talleres gráficos Banco Popular.

Arango, A. (1925). Concejo municipal, informe del presidente, 1923-1925. Manizales: Tipografía el Ruiz.

Archivo Historial de Manizales. (1920). Manizales: Centro de Estudios Histórico de Manizales.

Bauman, Z. (2001). La globalización. Consecuencias humanas. México: Fondo de Cultura Económica.

Carlos, A. (2003). São Paulo: dinâmica urbana e metropolização. Revista Território, (11), 77-89. Recuperado de http://www.revistaterritorio.com.br/ pdf/11_12_13_6_sao_paulo.pdf.

Carlos, A. (2001). Espaço-tempo na metrópole: a fragmentação da vida cotidiana. Sao Paulo: Contexto.

Certeau, M., Giard, L., y Mayol, P. (1999). La invención de lo cotidiano 2. Habitar, cocinar. México: Universidad Iberoamericana.

Davis, M. (2007). Planeta de ciudades miseria. Madrid: Foca, ediciones y distribuciones generales.

Escallón, C. (2010). Mercado informal de alquiler: nueva puerta de acceso a los asentamientos populares. En Arrendamiento y vivienda popular en Colombia 
como alternativa habitacional. Bogotá: Ediciones Uniandes.

Foucault, M. (1979). Microfísica del poder. Madrid: Las ediciones de La Piqueta

Fraser, N. (2008). Escalas de justicia. Barcelona: Heder.

Giraldo, H. (1985). Monografía arquitectónica de Manizales 1920-1970. Manizales: Universidad Nacional de Colombia.

Giraldo, L. (2001). Modernización e industrialización en el antiguo Caldas. Manizales: Editorial Universidad de Caldas.

Giraut, F. (2008) Conceptualiser le territoire. Historiens et géographes, (403), 57-67.

Harvey, D. (1973). Urbanismo y desigualdad social. Madrid, España: Siglo XXI.

Jiménez, L.C. (2009). Espacialidad urbana de propietarios e inquilinos en sectores populares. El caso de Bogotá 1938-2000. En M. Castillo (Ed.), Procesos urbanos informales y territorio. Ensayos en torno a la construcción de sociedad, territorio y ciudad. Bogotá: Universidad Nacional de Colombia.

Lefebvre, H. (2013). La producción del espacio. Madrid: Capitán Swing Libros.

Lefebvre, H. (1978). El derecho a la ciudad. Barcelona: Ediciones 62.

Lindón, A. (2007). Los imaginarios urbanos y el constructivismo geográfico: los hologramas espaciales. EURE, 33 (99), 31-46. https://doi.org/10.4067/ S0250-71612007000200004.

102 revista invi 33(94): 79-103, noviembre 2018
Mattos, C.d. (2010). Globalización y metamorfosis metropolitana en América Latina. De la ciudad a lo urbano generalizado. Revista de Geografía Norte Grande, (47), 81-104. https://doi.org/10.4067/ S0718-34022010000300005

Mattos, C.d. (1999). Santiago de Chile, globalización y expansión metropolitana: lo que existía sigue existiendo. EURE, 25(76), 29-56. https://doi. org/10.4067/S0250-71611999007600002.

Pradilla, E., Galván, F., y Márquez, L. (2012) Cambios económicos y morfológicos en la zona metropolitana del Valle de México. En E. Duhau (Comp.), Ciudad de México: la construcción permanente de la metrópoli. Quito, Ecuador: OLACCHI.

Raffestin, C. (1989) La practique politique et le découpage territorial. Treballs de la Societat Catalana de Geografia, 4(17), 111-114. Recuperado de http://revistes.iec.cat/index.php/TSCG/article/ view/36528/36521.

Rawls, J. 2012. Teoría de la justicia. México: Fondo de Cultura Económica.

Ricoeur, P. (2006). Caminos del reconocimiento. Tres estudios. México: Fondo de Cultura Económica.

Robledo, J.E. (1992). La arquitectura y el desarrollo urbano en la historia de Manizales 1846-1930. Manizales: Universidad Nacional de Colombia.

Safa, P. y Aceves. J. (2006). La experiencia de la exclusión social y urbana en torno a la vivienda. En P. Ramírez, y M. Aguilar (Coords.), Pensar y habitar la ciudad. Afectividad, memoria y significado en el espacio urbano contemporáneo (pp. 51-68). México: Anthropos. 
Santos, M. (1990). Metrópole corporativa fragmentada. O caso de São Paulo. São Paulo: Nobe.

Smolka, M. (2002). Regularización de la ocupación del suelo urbano: el problema que es parte de la solución, la solución que es parte del problema. Cambridge: Lincoln Institute of Land Policy.

Soja, E. (2010). Seeking spatial justice. Minneapolis: University of Minnesota Press.

Soja, E. (2008). Postmetrópolis. Estudios críticos sobre las ciudades y las regiones. Madrid: Traficantes de sueños.

Young, I.M. (2000). La justicia y la politica de la diferencia. Madrid: Cátedra.

Zambrano, F. y Bernard, 0. (1993). Ciudad y territorio. El proceso de poblamiento en Colombia. Bogotá: Academia de Historia Bogotá, Instituto Francés de Estudios Andinos, Fundación de Estudios Históricos Misión Colombia. 